\title{
Feasibility Study of Modified Single-Particle Model for Composite Cathode at High-Rate Discharge Ikuo GOTO, ${ }^{a}$ * Hirokazu OHKUMA, ${ }^{b}$ and Hiroo HONGO ${ }^{b}$
}

\author{
${ }^{a}$ EV Powertrain Development Department, Mitsubishi Motors Corporation, \\ 1-1 Kawagoe, Nikki, Okazaki, Aichi 444-2148, Japan \\ b EV Component Research Department, Mitsubishi Motors Corporation, \\ 1 Nakashinkiri, Hashime, Okazaki, Aichi 444-8501, Japan
}

* Corresponding author: ikuo.goto@mitsubishi-motors.com

\begin{abstract}
In order to simulate high-rate discharge behavior of lithium-ion batteries with composite cathode materials, we applied a single-particle model to each cathode material. In the model, we also included the lithium-ion concentration distribution within the electrolyte to calculate the potential profiles in the liquid phase as well as the temperature dependence of both the diffusion behavior of lithium-ions and the charge-transfer rate constant at the solid-electrolyte interface. The potential responses under high-rate discharge were successfully simulated. In this model, the molar flux of each cathode material was determined under the condition that the closed circuit potential of each single-particle should be equal, and the potential distribution in the electrolyte was calculated using a parabolic lithium-ion concentration. The use of approximate analytical solutions for the diffusion equations enabled the reduction of computational time. The validity of the model was confirmed by the experiments using a half-cell of the composite cathode.
\end{abstract}

(c) The Electrochemical Society of Japan, All rights reserved.

Keywords : Lithium-ion Battery, Simulation, Battery Modeling, Single-particle Model

\section{Introduction}

Development of powertrains and battery management systems (BMS) for plug-in hybrid or battery electric vehicles (EVs) requires a huge amount of battery data under various operating conditions. However, it is not realistic to perform battery tests under all possible operating conditions; therefore the importance of battery simulation models that can precisely predict battery behavior under various conditions is increasing.

The so-called pseudo two dimensional (P2D) model has been proposed as an accurate physics-based battery model. ${ }^{1-3}$ The P2D models can predict battery behavior accurately, but in general they require long computational time.

The single-particle (SP) model has been proposed in order to reduce the computational load of the P2D model. ${ }^{4-7}$ In the SP model, each electrode is represented by a single spherical particle and lithium-ion $\left(\mathrm{Li}^{+}\right)$diffusion in the electrolyte is not taken into account. In spite of having less computational load than the P2D model, the SP model can simulate the output voltage as well as the heat generation characteristics.

Although they are easy to implement and save much computational time, simulations based on the SP model have poor accuracy under high-rate conditions $(>1 \mathrm{C})$; therefore the conventional SP model is not sufficient for the purpose of the development of powertrains or for BMS for EVs.

The poor accuracy under high-rate conditions is attributed to the neglect of the $\mathrm{Li}^{+}$diffusion in the electrolyte. Inclusion of the $\mathrm{Li}^{+}$ diffusion phenomena in the electrolyte into the SP model has been proposed in order to improve the high-rate feasibility, ${ }^{8-10}$ and these models have shown better accuracy. In addition to the liquid phase diffusion, inclusion of the temperature dependence of the physical properties (such as the diffusion coefficient and the charge-transfer rate constant) into the SP model has led to a significant improvement in simulation accuracy. ${ }^{9}$

However, the SP model with the liquid phase diffusion and the temperature dependent parameters is not yet suitable for applying to the batteries for EVs because the modern batteries for EVs have composite cathodes of several active materials. ${ }^{11}$ Actually, the conventional SP model can only treat the mixture of various active materials in the cathode as some kind of "averaged" single-particle with the size, composition, and other properties of these materials, and thus the SP model would result in poor simulation accuracy. An attempt of applying the SP model to each active material in the composite cathode has been proposed. Marcicki et al. ${ }^{12}$ successfully explained the capacity fade mechanism by modifying the SP model for the composite cathode, however, they have not yet explicitly dealt with the model feasibility on simulation of discharge behavior at high-rate current.

In this report, we focused on the high-rate feasibility of the SP model, which included the liquid phase transport phenomena and the temperature dependence of the physical parameters applied to each active material in the composite cathode for EVs. The validity of the model was confirmed by comparison with the experiments at various discharge rates and temperatures.

\section{Modeling}

In this work, we studied two models for a composite cathode using lithium manganese oxide (LMO) and lithium nickel manganese cobalt oxide (NMC). In the first model (model A), the SP model is applied to the composite cathode regardless of the type of active material. In the second model (model B), the SP model is applied to each active material of the composite cathode. The transport phenomena of $\mathrm{Li}^{+}$in the electrolyte as well as the temperature dependence of the physical parameters are also considered in both models.

Figure 1 shows a schematic diagram of a half-cell with a lithiummetal anode, a separator, and a composite cathode. The transport phenomena of $\mathrm{Li}^{+}$are considered only in $x$-direction (cell thickness direction). 


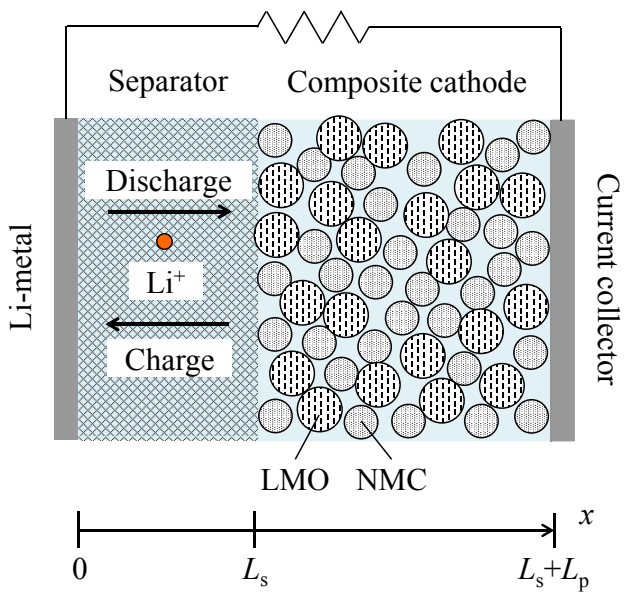

Figure 1. (Color online) Schematic diagram of a half-cell. It is composed of a lithium-metal, a separator, and a composite cathode. The pores of each region are filled with the electrolyte.

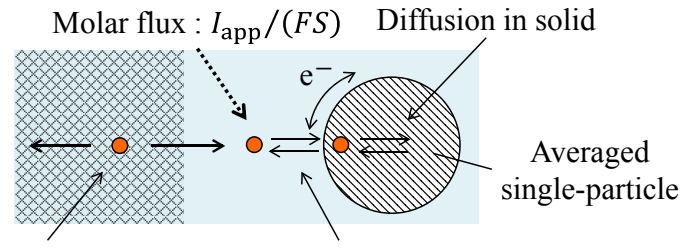

Diffusion in electrolyte Charge-transfer reaction

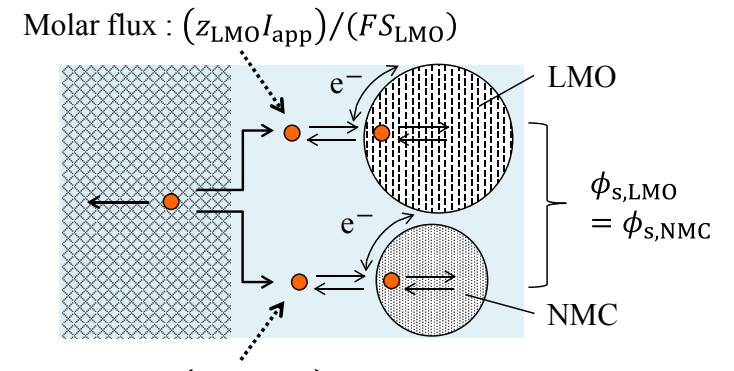

Molar flux : $\left(z_{\mathrm{NMC}} I_{\mathrm{app}}\right) /\left(F S_{\mathrm{NMC}}\right) \quad z_{\mathrm{LMO}}+z_{\mathrm{NMC}}=1$

Figure 2. (Color online) Schematic diagrams of simulation models: (a) shows model A where SP model is applied to the composite cathode regardless of the type of active material, and (b) shows model B where SP model is applied independently to each particle of LMO and NMC. In model B, the molar flux is distributed to each active material. Both models include the liquid phase $\mathrm{Li}^{+}$transport phenomena.

Figure 2(a) shows a schematic diagram of model A. To formulate model A, we followed the work of Tanim et al. ${ }^{9}$ The details of the formalism and the meanings of variables are summarized in Appendix.

We derived an approximate analytical solution of the $\mathrm{Li}^{+}$ concentration and potential difference in the electrolyte as follows. We assumed a parabolic $\mathrm{Li}^{+}$concentration in the separator (subscript $i=\mathrm{s}$ ) and the cathode $(i=\mathrm{p})$ as

$$
c_{\mathrm{e}, i}(x, t)=c_{i, 0}(t)+c_{i, 1}(t) x+c_{i, 2}(t) x^{2} .
$$

From Eq. (1) and the diffusion equation in the electrolyte (see Eqs. (14) and (15) in Table 2), by using Integral Method Approximation, ${ }^{13}$ the relationship

$$
\frac{c_{\mathrm{e}, i}(x, s)}{I_{\mathrm{app}}(s)}=\frac{a_{i, 0}(x)+a_{i, 1}(x) s}{b_{i, 0}+b_{i, 1} s}
$$

was derived, where $s$ denotes the Laplace operator and the coefficients $a_{i, 0}, \ldots, b_{i, 1}$ denote the constants determined by the cell design parameters $\left(A, L_{i}, \varepsilon_{\mathrm{e}, i}\right)$ and the transport properties $\left(D_{\mathrm{e}, \mathrm{eff}, i}, t_{+}{ }^{0}\right)$. To calculate the overpotential (see Eq. (21) in Appendix), we used the value of the liquid phase $\mathrm{Li}^{+}$concentration at the center point of the cathode region. From Eq. (2) and the charge conservation equation (see Eqs. (16) and (17) in Table 2), the liquid phase potential difference between the anode and the cathode was derived as

$$
\frac{\Delta \phi_{\mathrm{e}}(s)}{I_{\mathrm{app}}(s)}=\frac{A_{0}+A_{1} s}{B_{0}+B_{1} s},
$$

where $A_{0}, \ldots, B_{1}$ denote the constants determined by the conductive properties $\left(\kappa_{\mathrm{eff}, i}\right.$ and $\left.\kappa_{\mathrm{d}, \mathrm{eff}, i}\right)$ in addition to the cell design parameters and transport properties described above. The approximate analytical solutions of the $\mathrm{Li}^{+}$concentration and potential difference in the electrolyte could be obtained by inverse Laplace transform of Eqs. (2) and (3), respectively.

The temperature dependence of the parameters in the model was included as follows. The solid phase diffusion coefficient of $\mathrm{Li}^{+}$and the charge-transfer rate constant at the solid-electrolyte interface were assumed to obey Arrhenius' law:

$$
\begin{aligned}
& D_{\mathrm{s}}(T)=D_{\mathrm{s}, \mathrm{ref}} \exp \left[\frac{E_{\mathrm{a}, \mathrm{Ds}}}{R}\left(\frac{1}{T_{\mathrm{ref}}}-\frac{1}{T}\right)\right], \\
& k(T)=k_{\mathrm{ref}} \exp \left[\frac{E_{\mathrm{a}, \mathrm{k}}}{R}\left(\frac{1}{T_{\text {ref }}}-\frac{1}{T}\right)\right] .
\end{aligned}
$$

The diffusion coefficient, ionic conductivity, and diffusional conductivity in the electrolyte were assumed to obey Eq. (6), Eq. (7), and Eq. (8), ${ }^{14}$ respectively:

$$
\begin{aligned}
& \log _{10} D_{\mathrm{e}}(T)=-8.43-\frac{54}{T-\left(229+5.0 \times 10^{-3} \times c_{\mathrm{e}, 0}\right)} \\
&- 2.2 \times 10^{-4} \times c_{\mathrm{e}, 0} \\
& \sqrt{\frac{\kappa(T)}{c_{\mathrm{e}, 0} \times 10^{-1}}=}\left(-10.5+0.074 T-6.96 \times 10^{-5} T^{2}\right) \\
&+c_{\mathrm{e}, 0} \times 10^{-3}\left(0.668-0.0178 T-2.8 \times 10^{-5} T^{2}\right) \\
&+c_{\mathrm{e}, 0}^{2} \times 10^{-6}\left(0.494-8.86 \times 10^{-4} T\right) \\
& \kappa_{\mathrm{d}}(T)=-\frac{2 R T \kappa(T)}{F}\left[0.601-0.24\left(c_{\mathrm{e}, 0} \times 10^{-3}\right)^{\frac{1}{2}}\right. \\
&\left.+0.982[1-0.0052(T-293)] \times\left(c_{\mathrm{e}, 0} \times 10^{-3}\right)^{\frac{3}{2}}\right]
\end{aligned}
$$

Figure 2(b) shows a schematic diagram of model B. The molar flux of $\mathrm{Li}^{+}$at each active material surface was determined in the same manner as Marcicki et al. ${ }^{12}$ The molar flux at each active material surface was

$$
j_{j}(t)=\frac{z_{j}(t) I_{\mathrm{app}}(t)}{F S_{j}},
$$

where $z_{j}$ denotes the current distribution factor, and subscript $j$ denotes LMO or NMC. The closed circuit potential of each active material single-particle should be equal:

$$
\phi_{\mathrm{s}, \mathrm{LMO}}\left(z_{\mathrm{LMO}}(t)\right)=\phi_{\mathrm{s}, \mathrm{NMC}}\left(z_{\mathrm{NMC}}(t)\right) \text {. }
$$

The sum of current distribution factor $z_{j}$ must be unity, or

$$
z_{\mathrm{LMO}}(t)+z_{\mathrm{NMC}}(t)=1 \text {. }
$$

By solving Eqs. (10) and (11), $z_{j}$ was obtained, then the molar flux could be calculated by using Eq. (9). In model B, Eqs. (4) and (5) were applied to each active material.

In order to reduce the computational load, we used an approximate analytical solution of the $\mathrm{Li}^{+}$concentration at the active material surface for both models (see Eq. (26) in Appendix).

The output potential was simulated by feeding the values of the applied current and the cell surface temperature to the model. 
Electrochemistry, 84(6), 432-437 (2016)

Table 1. Summary of model parameters

\begin{tabular}{|c|c|c|c|c|c|}
\hline \multirow{2}{*}{ Parameter } & \multirow{2}{*}{ Symbol } & \multirow{2}{*}{ Unit } & \multirow{2}{*}{ Model A } & \multicolumn{2}{|c|}{ Model B } \\
\hline & & & & $j=\mathrm{LMO}$ & $j=\mathrm{NMC}$ \\
\hline Open circuit potential $^{\mathrm{a}}$ & $U_{j}$ & V vs. $\mathrm{Li}^{+} / \mathrm{Li}$ & $\mathrm{C} / 100$ discharge curve & Ref. 15 & Ref. 16 \\
\hline Maximum $\mathrm{Li}^{+}$concentration & $c_{\mathrm{s}, \max , j}$ & $\mathrm{~mol} \mathrm{~m}^{-3}$ & $3.0 \times 10^{4}$ & $2.3 \times 10^{4}$ & $4.9 \times 10^{4}$ \\
\hline Mean particle radius & $R_{\mathrm{p}, j}$ & $\mathrm{~m}$ & $7.0 \times 10^{-6}$ & $8.0 \times 10^{-6}$ & $2.0 \times 10^{-6}$ \\
\hline Solid phase diffusion coefficient ${ }^{\mathrm{a}}$ & $D_{\mathrm{s}, \mathrm{ref}, j}$ & $\mathrm{~m}^{2} \mathrm{~s}^{-1}$ & $1.4 \times 10^{-14}$ & $1.1 \times 10^{-14}$ & $2.1 \times 10^{-14}$ \\
\hline Charge-transfer rate constant ${ }^{\mathrm{a}}$ & $k_{\mathrm{ref}, j}$ & $\mathrm{~m}^{2.5} \mathrm{~mol}^{-0.5} \mathrm{~s}^{-1}$ & $2.3 \times 10^{-11}$ & $2.7 \times 10^{-11}$ & $1.4 \times 10^{-11}$ \\
\hline Activation energy for $D_{s}$ & $E_{\mathrm{a}, \mathrm{Ds}, j}$ & $\mathrm{~J} \mathrm{~mol}^{-1}$ & $2.3 \times 10^{4}$ & $2.2 \times 10^{4}$ & $2.5 \times 10^{4}$ \\
\hline Activation energy for $k$ & $E_{\mathrm{a}, \mathrm{k}, j}$ & $\mathrm{~J} \mathrm{~mol}^{-1}$ & $3.2 \times 10^{4}$ & $3.2 \times 10^{4}$ & $3.3 \times 10^{4}$ \\
\hline Active material volume fraction ${ }^{b}$ & $\varepsilon_{\mathrm{s}, j}$ & - & 0.50 & 0.30 & 0.14 \\
\hline Porosity of composite cathode ${ }^{c}$ & $\varepsilon_{\mathrm{e}, \mathrm{p}}$ & - & & 0.30 & \\
\hline Porosity of separator ${ }^{\mathrm{c}}$ & $\varepsilon_{\mathrm{e}, \mathrm{s}}$ & - & & 0.40 & \\
\hline Thickness of composite cathode & $L_{\mathrm{p}}$ & $\mathrm{m}$ & & $8.0 \times 10^{-5}$ & \\
\hline Thickness of separator & $L_{\mathrm{S}}$ & $\mathrm{m}$ & & $3.0 \times 10^{-5}$ & \\
\hline Electrode area & $A$ & $\mathrm{~m}^{2}$ & & $7.5 \times 10^{-4}$ & \\
\hline Initial electrolyte concentration & $c_{\mathrm{e}, 0}$ & $\mathrm{~mol} \mathrm{~m}^{-3}$ & & $1.0 \times 10^{3}$ & \\
\hline Transference number ${ }^{\mathrm{c}}$ & $t_{+}{ }^{0}$ & - & & 0.38 & \\
\hline
\end{tabular}

${ }^{\text {aValues at }} T_{\text {ref }}=298.15 \mathrm{~K}$.

${ }^{b}$ Estimated by non-linear least squares fitting. ${ }^{12,17}$

'Ref. 9.

The current and temperature values were measured in the experiments described below. All the calculations were performed by MATLAB $^{\circledR}$.

\section{Experimental}

In order to obtain the parameters and to confirm the validity of the model, the discharge characteristics of the half-cell with the composite cathode were evaluated at various current rates and temperatures.

The working electrode for the half-cell was prepared by cutting out the composite cathode with a thickness of $80 \mu \mathrm{m}$ from a commercially available battery to sheets of $15 \times 25 \mathrm{~mm}^{2}$. Lithiummetals were used as the counter and reference electrodes. A solution of $1 \mathrm{M} \mathrm{LiPF}_{6}$ in ethylene carbonate: diethyl carbonate $(3: 7, \mathrm{v} / \mathrm{v})$ mixture was used as an electrolyte. The mean particle radius in the composite cathode was determined as $\sim 8 \mu \mathrm{m}$ for LMO and $\sim 2 \mu \mathrm{m}$ for NMC from the scanning electron micrograph. Following the procedure given in Refs. 12 and 17, the active material volume fraction was estimated to be 0.30 for LMO and 0.14 for NMC. In this work, the porosity of each region was assumed to be the value in Ref. 9.

The parameters used for the model calculations are summarized in Table 1 . The solid phase $\mathrm{Li}^{+}$diffusion coefficient and chargetransfer rate constant of each active material were obtained by Galvanostatic Intermittent Titration Technique ${ }^{18}$ and Electrochemical Impedance Spectroscopy, ${ }^{19}$ respectively. The solid phase diffusion coefficient was calculated by applying Eq. (1) in Ref. 18 to the potential variation for 50 seconds from the beginning of discharge. The charge-transfer rate constant was calculated using Eq. (2) in Ref. 19 under the assumption that the diameter of the semicircle in the Nyquist plot is the charge-transfer resistance. In order to obtain these parameters of LMO and NMC, the parameters of each active material such as $U_{j}, c_{\mathrm{s}, \max , j}, R_{\mathrm{p}, j}$, and $\varepsilon_{\mathrm{s}, j}$ were used in the above calculations. Although the solid phase diffusion coefficient and the charge-transfer rate constant depend on the potential, for simplicity we used the values at the potential of $\sim 4.1 \mathrm{~V}$ vs. $\mathrm{Li}^{+} / \mathrm{Li}$ and $\sim 3.7 \mathrm{~V}$ vs. $\mathrm{Li}^{+} / \mathrm{Li}$, for LMO and NMC, respectively, where each plays a dominant role as shown in Fig. 4.
To compare with the simulation, the discharge characteristics of the half-cell were measured under the constant discharge rates of $1 \mathrm{C}, 2 \mathrm{C}, 3 \mathrm{C}$, and $5 \mathrm{C}$ at ambient temperatures of $10^{\circ} \mathrm{C}, 25^{\circ} \mathrm{C}$, and $40^{\circ} \mathrm{C}$. The half-cell potential, applied current, and cell surface temperature were acquired at each predetermined time interval.

\section{Results and Discussion}

Figure 3(a)-3(c) show the simulated potential of the composite cathode by model A and B, and measured potential with the half-cell in the experiments at various discharge rates and temperatures. Compared with model A, model B shows much better accuracy at low potential $\left(<3.8 \mathrm{~V}\right.$ vs. $\left.\mathrm{Li}^{+} / \mathrm{Li}\right)$. The simulation errors of model B at $25^{\circ} \mathrm{C}$ are within approximately $40 \mathrm{mV}$ at discharge rates up to $3 \mathrm{C}$, in the range above $3.6 \mathrm{~V}$ vs. $\mathrm{Li}^{+} / \mathrm{Li}$. This result indicates that applying the SP model to each active material improves the accuracy of the simulation at high-rate discharge. As the temperature dependence of the parameters is included, results of model B show good agreement with experiments at various temperatures.

Figure 4 shows the molar flux ratios of LMO and NMC with respect to the entire composite cathode at $25^{\circ} \mathrm{C}$. According to Fig. 4 , LMO plays a dominant role at high potential and NMC does the same at low. The similar potential dependence of the valence numbers of the transition metals in composite cathodes has been observed by x-ray diffraction, ${ }^{20}$ therefore our current distribution model is reasonable. The molar flux ratio also depends on the discharge rate as shown in Fig. 4. This information should be useful for the design of mixture ratios in composite cathodes.

Figure 5 shows the absolute errors of the potential simulated by model $\mathrm{B}$ at $25^{\circ} \mathrm{C}$. In the potential above $3.6 \mathrm{~V} \mathrm{vs} \mathrm{Li}^{+} / \mathrm{Li}$, the simulations show good agreement with experiments, and the errors are less than $\sim 40 \mathrm{mV}$ ( $1 \%$ relative error with respect to the cathode potential) at discharge rates below $3 \mathrm{C}$.

On the other hand, significant simulation errors can be observed in both models at the highest rates in Fig. 3(a)-3(c). Albertus et al. have reported a similar result in which the simulation significantly overestimated the discharge potential at rate of $5 \mathrm{C}$ or higher. ${ }^{21}$ Albertus et al. have attributed the discrepancy between the simulations and experiments at high-rates to the neglect in the 

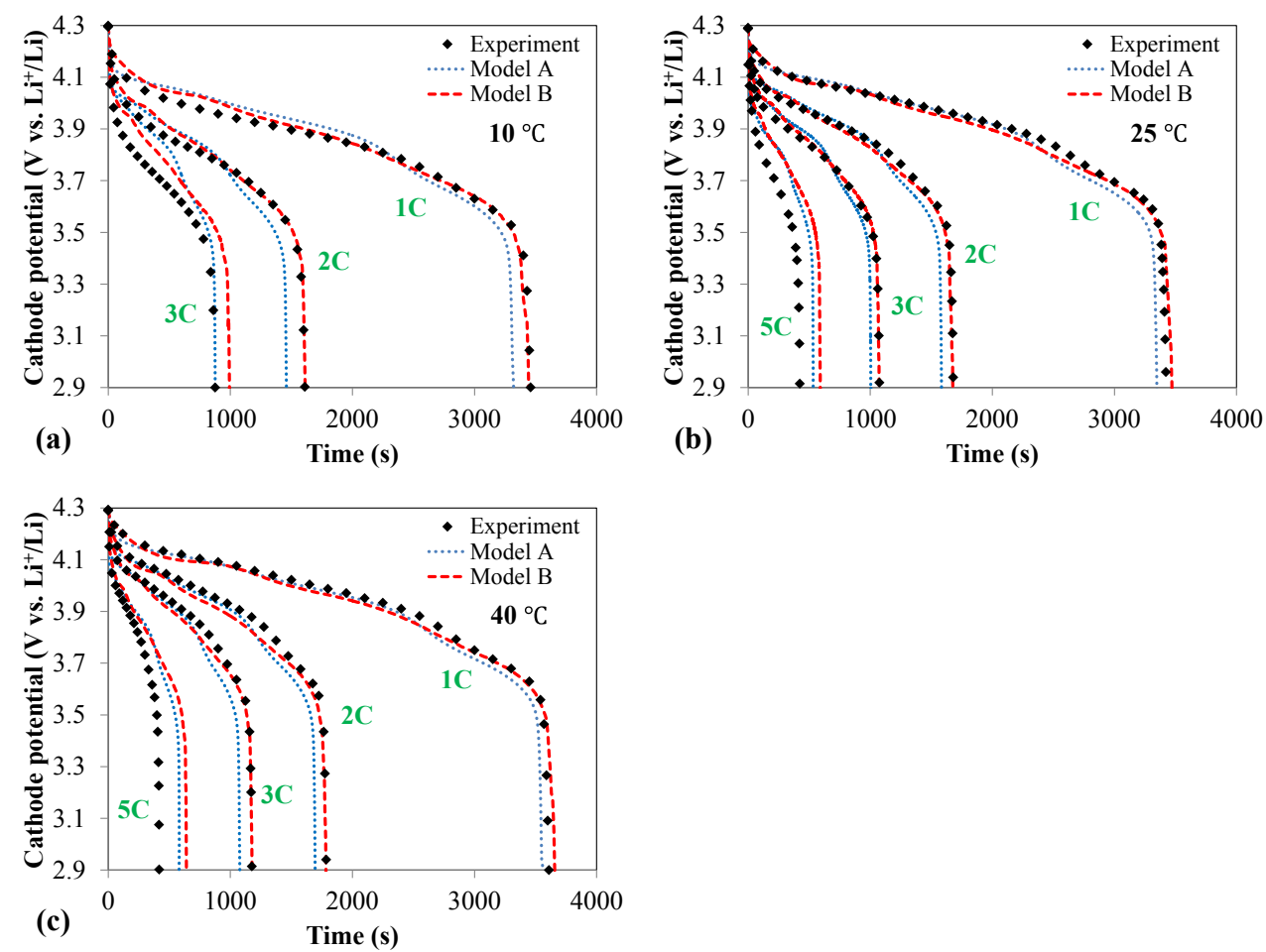

Figure 3. (Color online) Comparison of the measured cathode potential to the simulation. (a) $10^{\circ} \mathrm{C}$, (b) $25^{\circ} \mathrm{C}$, and (c) $40^{\circ} \mathrm{C}$.

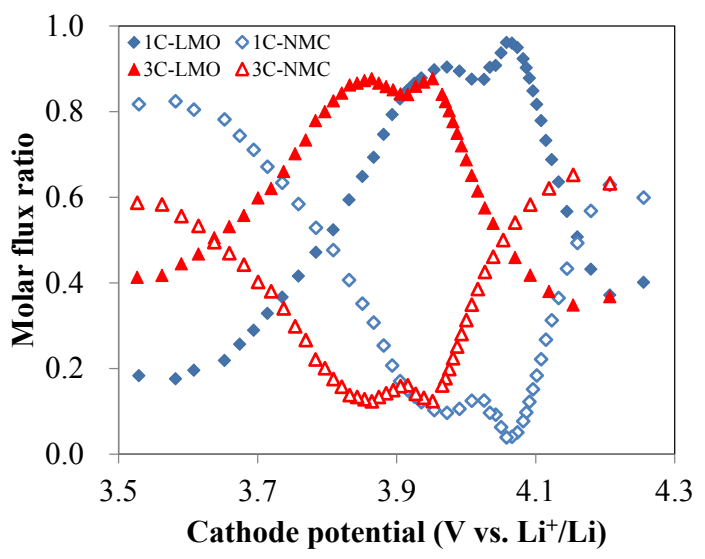

Figure 4. (Color online) Cathode potential dependence of the molar flux ratios in the composite cathode at $25^{\circ} \mathrm{C}$.

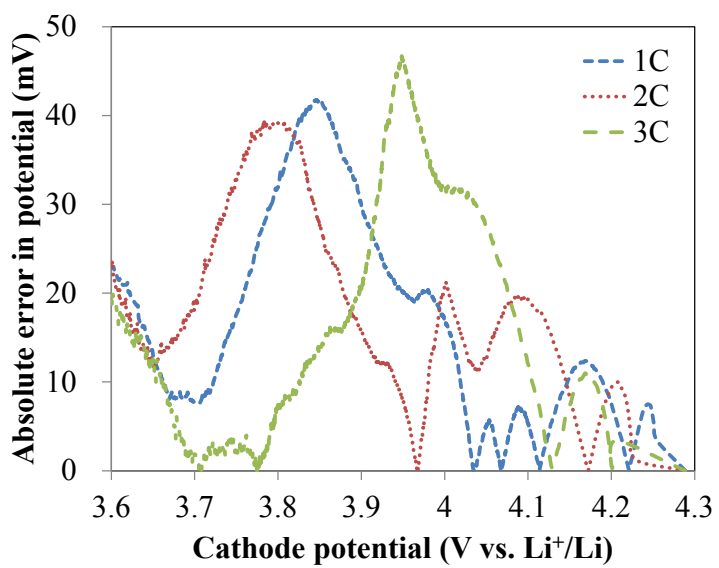

Figure 5. (Color online) Absolute errors of the potential calculated by model $\mathrm{B}$ at different discharge rates at $25^{\circ} \mathrm{C}$.

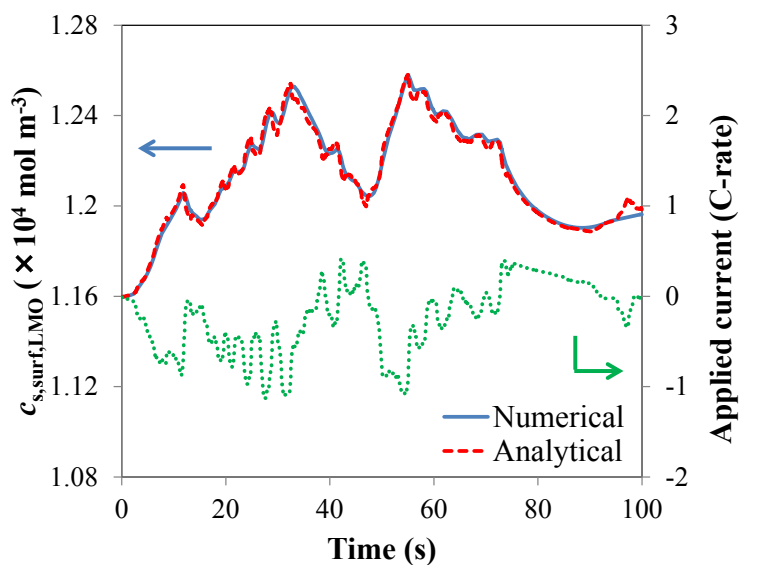

Figure 6. (Color online) Comparison of the numerical and analytical solutions of $\mathrm{Li}^{+}$concentration at $\mathrm{LMO}$ single-particle surface under the pulse current.

model of the porous electrode microstructure, a dependence of the electronic conductivity of the active material on the composition of lithium, or a voltage drop by some resistive film formed at the surface of the lithium-metal negative electrode.

Although the above described SP model is rather elaborate, the amount of computational load was still kept small because the approximate analytical solutions were used for the diffusion equations in both the solid and electrolyte phases. For example, the analytical solution for the solid phase diffusion equation (by using Eq. (26) in Appendix with $m=20$ ) required only one twentieth of the computational time with the exact numerical solution, while the error of the approximate solution was negligibly small. Figure 6 shows the comparison of the approximate analytical solution to the exact numerical $\mathrm{Li}^{+}$concentration of LMO single-particle surface under the pulse current. The exact numerical solution was obtained by using MATLAB ${ }^{\circledR}$ PDE solver "pdepe" by dividing the radius of the spherical active material particle into 50 meshes. The difference between the approximate and exact solution was less than $0.4 \%$. 
Electrochemistry, 84(6), 432-437 (2016)

Table 2. Summary of model equations and boundary conditions

\begin{tabular}{|c|c|c|c|}
\hline Equations & & Boundary conditions ${ }^{\mathrm{a}}$ & \\
\hline $\begin{array}{l}\text { Diffusion in solid phase } \\
\qquad \frac{\partial c_{\mathrm{s}}}{\partial t}=\frac{D_{\mathrm{s}}}{r^{2}} \frac{\partial}{\partial r}\left(r^{2} \frac{\partial c_{\mathrm{s}}}{\partial r}\right)\end{array}$ & (12) & $\begin{array}{c}\left.\frac{\partial c_{\mathrm{s}}}{\partial r}\right|_{r=0}=0 \\
-\left.\left(D_{\mathrm{s}} \frac{\partial c_{\mathrm{s}}}{\partial r}\right)\right|_{r=R_{\mathrm{p}}}=j\end{array}$ & (13) \\
\hline $\begin{array}{l}\text { Diffusion in electrolyte }{ }^{\mathrm{b}} \\
\qquad \begin{array}{c}\varepsilon_{\mathrm{e}} \frac{\partial c_{\mathrm{e}}}{\partial t}=D_{\mathrm{e}, \mathrm{eff}} \frac{\partial^{2} c_{\mathrm{e}}}{\partial x^{2}}+a_{\mathrm{s}}\left(1-t_{+}^{0}\right) j \\
D_{\mathrm{e}, \mathrm{eff}}=D_{\mathrm{e}} \times \varepsilon_{\mathrm{e}}^{\frac{3}{2}} \\
a_{\mathrm{s}}=\frac{3 \varepsilon_{\mathrm{s}}}{R_{\mathrm{p}}}\end{array}\end{array}$ & (14) & $\begin{array}{c}\left.D_{\mathrm{e}, \mathrm{eff}, \mathrm{s}} \frac{\partial c_{\mathrm{e}, \mathrm{s}}}{\partial x}\right|_{x=0}=\frac{\left(1-t_{+}^{0}\right)}{F A} I_{\mathrm{app}} \\
\left.D_{\mathrm{e}, \mathrm{eff}, \mathrm{s}} \frac{\partial c_{\mathrm{e}, \mathrm{s}}}{\partial x}\right|_{x=L_{\mathrm{s}}}=\left.D_{\mathrm{e}, \mathrm{eff}, \mathrm{p}} \frac{\partial c_{\mathrm{e}, \mathrm{p}}}{\partial x}\right|_{x=L_{\mathrm{s}}} \\
\left.\frac{\partial c_{\mathrm{e}, \mathrm{p}}}{\partial x}\right|_{x=L_{\mathrm{s}}+L_{\mathrm{p}}}=0 \\
c_{\mathrm{e}, \mathrm{s}}\left(L_{\mathrm{s}}, t\right)=c_{\mathrm{e}, \mathrm{p}}\left(L_{\mathrm{s}}, t\right)\end{array}$ & $(15)$ \\
\hline $\begin{array}{l}\text { Charge conservation in electrolyte }{ }^{\mathrm{b}} \\
\qquad \begin{array}{c}\kappa_{\mathrm{eff}} \frac{\partial^{2} \phi_{\mathrm{e}}}{\partial x^{2}}+\frac{\kappa_{\mathrm{d}, \mathrm{eff}}}{c_{\mathrm{e}, 0}} \frac{\partial^{2} c_{\mathrm{e}}}{\partial x^{2}}+a_{\mathrm{s}} F j=0 \\
\kappa_{\text {eff }}=\kappa \times \varepsilon_{\mathrm{e}^{\frac{3}{2}}} \\
\kappa_{\mathrm{d}, \mathrm{eff}}=\kappa_{\mathrm{d}} \times \varepsilon_{\mathrm{e}}^{\frac{3}{2}}\end{array}\end{array}$ & (16) & $\begin{array}{c}\left.\left(\kappa_{\mathrm{eff}, \mathrm{s}} \frac{\partial \phi_{\mathrm{e}, \mathrm{s}}}{\partial x}+\frac{\kappa_{\mathrm{d}, \mathrm{eff}, \mathrm{s}}}{c_{\mathrm{e}, 0}} \frac{\partial c_{\mathrm{e}, \mathrm{s}}}{\partial x}\right)\right|_{x=L_{\mathrm{s}}}=\left.\left(\kappa_{\mathrm{eff}, \mathrm{p}} \frac{\partial \phi_{\mathrm{e}, \mathrm{p}}}{\partial x}+\frac{\kappa_{\mathrm{d}, \mathrm{eff}, \mathrm{p}}}{c_{\mathrm{e}, 0}} \frac{\partial c_{\mathrm{e}, \mathrm{p}}}{\partial x}\right)\right|_{x=L_{\mathrm{s}}} \\
\left.\frac{\partial \phi_{\mathrm{e}, \mathrm{p}}}{\partial x}\right|_{x=L_{\mathrm{s}}+L_{\mathrm{p}}}=0 \\
\phi_{\mathrm{e}, \mathrm{s}}(0, t)=0 \\
\phi_{\mathrm{e}, \mathrm{s}}\left(L_{\mathrm{s}}, t\right)=\phi_{\mathrm{e}, \mathrm{p}}\left(L_{\mathrm{s}}, t\right)\end{array}$ & (17) \\
\hline
\end{tabular}

Charge-transfer at solid-electrolyte interface

$$
\begin{aligned}
& j=2 k c_{\mathrm{e}^{\frac{1}{2}}}\left(c_{\mathrm{s}, \max }-c_{\mathrm{s}, \text { surf }}\right)^{\frac{1}{2}} c_{\mathrm{s}, \operatorname{surf}}{ }^{\frac{1}{2}} \sinh \left(\frac{F}{2 R T} \eta\right) \\
& \eta=\phi_{\mathrm{s}}-\phi_{\mathrm{e}}-U\left(c_{\mathrm{s}, \text { surf }}\right)
\end{aligned}
$$

${ }^{\mathrm{a}} I_{\text {app }}$ is defined as positive at charge.

${ }^{\mathrm{b}} D_{\mathrm{e}}, \kappa$, and $\kappa_{\mathrm{d}}$ are given by Eqs. (6), (7), and (8), respectively.

\section{Conclusion}

We studied the feasibility of the SP model, which includes the $\mathrm{Li}^{+}$diffusion in the electrolyte and the temperature dependence of the parameters, under high-rate conditions. By applying the SP model to each active material in the composite cathode the highrate discharge behavior could be successfully predicted. At room temperature, the absolute error was within $\sim 40 \mathrm{mV}$ at rates below $3 \mathrm{C}$.

\section{Acknowledgments}

The authors thank their colleagues in EV Component Research Department of Mitsubishi Motors Corporation for their assistance in the experiments.

\section{Appendix}

\section{Governing equations}

The following equations were employed to describe $\mathrm{Li}^{+}$behavior in the composite cathode and separator: the diffusion equations for both the solid and liquid phases, the linearized charge conservation law in the electrolyte, and the charge-transfer equation at the solidelectrolyte interface. These equations and their boundary conditions are summarized in Table 2. The meanings of the variables are shown in List of Symbols.

\section{Detailed derivation of expressions for the composite cathode potential}

In the $\mathrm{SP}$ model, the molar flux of $\mathrm{Li}^{+}$at each active material surface is generally expressed as Eq. (9), where the subscript $j$ denotes the active material type. In model A, the active materials were not distinguished, and thus the current distribution factor $z_{j}$ was set to unity. In model $\mathrm{B}$, on the other hand, $j$ is identified for each active material. In Eq. (9), the symbol $S_{j}$ denotes the electroactive area of each active material, and is expressed by

$$
S_{j}=\frac{3 \varepsilon_{\mathrm{s}, j} A L_{\mathrm{p}}}{R_{\mathrm{p}, j}} .
$$

Substituting Eq. (9) into Eq. (18), and then solving for $\eta$ results in the formula

$$
\eta_{j}(t)=\frac{2 R T}{F} \sinh ^{-1}\left[\frac{z_{j}(t) I_{\mathrm{app}}(t)}{2 F S_{j} k_{j} c_{\mathrm{e}, \mathrm{p}}(t)^{\frac{1}{2}}\left(c_{\mathrm{s}, \mathrm{max}, j}-c_{\mathrm{s}, \mathrm{surf}, j}(t)\right)^{\frac{1}{2}} c_{\mathrm{s}, \mathrm{surf}, j}(t)^{\frac{1}{2}}}\right],
$$

where the overpotential of each active material $\eta_{j}$ is expressed as a formula which depends on $z_{j} I_{\text {app }}$ and $c_{\mathrm{s}, \mathrm{surf}, j}$.

Using the relation of Eq. (19), Eq. (10) can be written as

$$
\begin{aligned}
\phi_{\mathrm{s}, \mathrm{LMO}} & =U_{\mathrm{LMO}}+\eta_{\mathrm{LMO}}+\Delta \phi_{\mathrm{e}} \\
& =U_{\mathrm{NMC}}+\eta_{\mathrm{NMC}}+\Delta \phi_{\mathrm{e}} \\
& =\phi_{\mathrm{s}, \mathrm{NMC}} .
\end{aligned}
$$

Eliminating $\Delta \phi_{\mathrm{e}}$ from Eq. (22) and writing explicitly in terms of $z_{j} I_{\text {app }}$ and $c_{\mathrm{s}, \mathrm{surf}, j}$ would result in 


$$
\begin{aligned}
& U_{\mathrm{LMO}}\left(c_{\mathrm{s}, \mathrm{surf}, \mathrm{LMO}}(t)\right)+\eta_{\mathrm{LMO}}\left(c_{\mathrm{s}, \mathrm{sur}, \mathrm{LMO}}(t), z_{\mathrm{LMO}}(t) I_{\mathrm{app}}(t)\right) \\
& \quad=U_{\mathrm{NMC}}\left(c_{\mathrm{s}, \mathrm{surf}, \mathrm{NMC}}(t)\right)+\eta_{\mathrm{NMC}}\left(c_{\mathrm{s}, \mathrm{surf}, \mathrm{NMC}}(t), z_{\mathrm{NMC}}(t) I_{\mathrm{app}}(t)\right) .
\end{aligned}
$$

Note that $c_{\mathrm{s}, \mathrm{surf}, j}$ depends on $z_{j} I_{\text {app }}$. Noting that the change in the $\mathrm{Li}^{+}$ concentration at the active material surface is slower than the charge-transfer reaction, we assumed $c_{\mathrm{s} \text {,surf }, j}\left(t_{k}\right) \approx c_{\mathrm{s}, \text { surf }, j}\left(t_{k-1}\right)$, where $t_{k}$ denotes the elapsed time at the $k$-th simulation step. Then Eq. (23) can be written as

$$
\begin{aligned}
U_{\mathrm{LMO}} & \left.\left(c_{\mathrm{s}, \mathrm{surf}, \mathrm{LMO}}\left(t_{k-1}\right)\right)+\eta_{\mathrm{LMO}}\left(c_{\mathrm{s}, \mathrm{surf}, \mathrm{LMO}}\left(t_{k-1}\right), z_{\mathrm{LMO}}\left(t_{k}\right) I_{\mathrm{app}} t_{k}\right)\right) \\
= & U_{\mathrm{NMC}}\left(c_{\mathrm{s}, \mathrm{surf}, \mathrm{NMC}}\left(t_{k-1}\right)\right) \\
& +\eta_{\mathrm{NMC}}\left(c_{\mathrm{s}, \mathrm{surf}, \mathrm{NMC}}\left(t_{k-1}\right), z_{\mathrm{NMC}}\left(t_{k}\right) I_{\mathrm{app}}\left(t_{k}\right)\right) .
\end{aligned}
$$

By solving Eqs. (11) and (24), $z_{j}$ can be obtained, and then the molar flux is calculated by Eq. (9). Substituting the molar flux

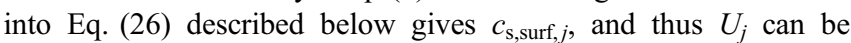
calculated. Then $\eta_{j}$ is given by Eq. (21) with $z_{j} I_{\text {app }}$ and $c_{\mathrm{s}, \text { surf }, j}$. Finally, the half-cell voltage of the composite cathode is obtained as

$$
V_{\mathrm{hc}}\left(t_{k}\right)=\phi_{\mathrm{s}, j}\left(t_{k}\right)=U_{j}\left(c_{\mathrm{s}, \mathrm{surf}, j}\left(t_{k-1}\right)\right)+\eta_{j}\left(t_{k}\right)+\Delta \phi_{\mathrm{e}}\left(t_{k}\right) .
$$

\section{Approximate analytical solution for Li-ion diffusion in solid particle}

The diffusion equation in solid phase, Eqs. (12) and (13), is solved by Pseudo-Steady State Method. ${ }^{22}$ The approximate analytical solution of $c_{\mathrm{s}, \mathrm{sur}, j}$ is given by

$$
\begin{aligned}
c_{\mathrm{s}, \mathrm{sur}, j}(t) & \\
= & c_{\mathrm{s}, 0, j}-\frac{3}{R_{\mathrm{p}, j}} \int_{0}^{t} j_{j}(\tau) d \tau-\frac{R_{\mathrm{p}, j}}{5 D_{\mathrm{s}, j}} j_{j}(t) \\
& +\frac{2 R_{\mathrm{p}, j}}{D_{\mathrm{s}, j}} \sum_{m=1}^{\infty}(-1)^{m} \frac{\left(1+\lambda_{m}^{2}\right)^{\frac{1}{2}}}{\lambda_{m}^{3}} \sin \left(\lambda_{m}\right) \\
& \times\left[j_{j}(t)-\frac{\lambda_{m}^{2} D_{\mathrm{s}, j}}{R_{\mathrm{p}, j}^{2}} \int_{0}^{t} j_{j}(\tau) \exp \left(\frac{\lambda_{m}^{2} D_{\mathrm{s}, j}}{R_{\mathrm{p}, j}^{2}}(\tau-t)\right) d \tau\right] .
\end{aligned}
$$

\section{List of Symbols}

$t$ : elapsed time (s)

$t_{k}: \quad$ elapsed time at $k$-th simulation step (s)

$s: \quad$ Laplace operator

$x$ : coordinate of cell thickness direction $(\mathrm{m})$

$r: \quad$ radial coordinate in a particle of active material $(\mathrm{m})$

$T: \quad$ cell surface temperature $(\mathrm{K})$

$T_{\text {ref: }} \quad$ reference temperature $(\mathrm{K})$

$R: \quad$ ideal gas constant $\left(\mathrm{J} \mathrm{mol}^{-1} \mathrm{~K}^{-1}\right)$

$F$ : $\quad$ Faraday constant $\left(\mathrm{C} \mathrm{mol}^{-1}\right)$

A: $\quad$ electrode area $\left(\mathrm{m}^{2}\right)$

$L_{i}$ : $\quad$ thickness of region $i(\mathrm{~m})$

$a_{s}: \quad$ specific interfacial area of solid-electrolyte $\left(\mathrm{m}^{-1}\right)$

$S_{j}: \quad$ electroactive area of active material $j\left(\mathrm{~m}^{2}\right)$

$R_{\mathrm{p}, j}: \quad$ mean particle radius of active material $j(\mathrm{~m})$

$\varepsilon_{\mathrm{s}, j}: \quad$ volume fraction of active material $j$

$\varepsilon_{\mathrm{e}, i}: \quad$ porosity of region $i$

$c_{\mathrm{s}, j}: \quad \mathrm{Li}^{+}$concentration of active material $j\left(\mathrm{~mol} \mathrm{~m}^{-3}\right)$

$c_{\mathrm{s}, 0, j}: \quad$ initial $\mathrm{Li}^{+}$concentration of active material $j\left(\mathrm{~mol} \mathrm{~m}^{-3}\right)$

$c_{\mathrm{s}, \text { surf }, j}$ : surface $\mathrm{Li}^{+}$concentration of active material $j\left(\mathrm{~mol} \mathrm{~m}^{-3}\right)$

$c_{\mathrm{s}, \text { max }, j}$ : maximum $\mathrm{Li}^{+}$concentration of active material $j\left(\mathrm{~mol} \mathrm{~m}^{-3}\right)$

$c_{\mathrm{e}, i}: \quad$ electrolyte concentration of domain $i\left(\mathrm{~mol} \mathrm{~m}^{-3}\right)$

$c_{\mathrm{e}, 0}: \quad$ initial electrolyte concentration $\left(\mathrm{mol} \mathrm{m}^{-3}\right)$

$U_{j}$ : open circuit potential of active material $j(\mathrm{~V})$ $\eta_{j}: \quad$ overpotential of active material $j(\mathrm{~V})$

$\phi_{\mathrm{s}, j}: \quad$ closed circuit potential of active material $j(\mathrm{~V})$

$\phi_{\mathrm{e}, i}: \quad$ electrolyte potential in region $i(\mathrm{~V})$

$V_{\mathrm{hc}}: \quad$ voltage of half-cell $(\mathrm{V})$

$I_{\text {app }}: \quad$ applied current (A/defined as positive at charge)

$j_{j}$ : $\quad$ pore-wall molar flux of active material $j\left(\mathrm{~mol} \mathrm{~m}^{-2} \mathrm{~s}^{-1}\right)$

$z_{j}$ : $\quad$ current distribution factor of active material $j$

$D_{\mathrm{s}, j}: \quad$ diffusion coefficient of $\mathrm{Li}^{+}$in active material $j\left(\mathrm{~m}^{2} \mathrm{~s}^{-1}\right)$

$E_{\mathrm{a}, \mathrm{Ds}, j}$ : activation energy for $D_{\mathrm{s}, j}\left(\mathrm{~J} \mathrm{~mol}^{-1}\right)$

$k_{j}$ : charge-transfer rate constant of active material $j$ $\left(\mathrm{m}^{2.5} \mathrm{~mol}^{-0.5} \mathrm{~s}^{-1}\right)$

$E_{\mathrm{a}, \mathrm{k}, j}:$ activation energy for $k_{j}\left(\mathrm{~J} \mathrm{~mol}^{-1}\right)$

$\lambda_{m}: \quad$ eigenvalue of $\tan \left(\lambda_{m}\right)=\lambda_{m}$

$D_{\mathrm{e}}$ : diffusion coefficient of electrolyte $\left(\mathrm{m}^{2} \mathrm{~s}^{-1}\right)$

$D_{\mathrm{e}, \text { eff }, i}$ : effective diffusion coefficient of electrolyte in region $i$ $\left(\mathrm{m}^{2} \mathrm{~s}^{-1}\right)$

$t_{+}{ }^{0}: \quad$ transference number of $\mathrm{Li}^{+}$in electrolyte

$\kappa: \quad$ ionic conductivity of electrolyte $\left(\mathrm{S} \mathrm{m}^{-1}\right)$

$\kappa_{\text {eff }, i}$ : effective ionic conductivity of electrolyte in region $i$ $\left(\mathrm{S} \mathrm{m}^{-1}\right)$

$k_{\mathrm{d}, \mathrm{eff}, i}$ : effective diffusional conductivity of electrolyte in region $i$ $\left(\mathrm{A} \mathrm{m}^{-1}\right)$

Subscripts

$i: \quad \mathrm{p}$ (= composite cathode) or $\mathrm{s}$ (= separator)

$j$ : $\quad$ LMO or $\mathrm{NMC}^{\mathrm{a}}$

$k$ : number of execution steps of the simulation

$m: \quad$ eigenvalue number of $\tan \left(\lambda_{m}\right)=\lambda_{m}$

ref: $\quad$ value at reference temperature

af $j$ is not distinguished, each parameter is the averaged value for $j$.

\section{References}

1. M. Doyle, T. F. Fuller, and J. Newman, J. Electrochem. Soc., 140, 1526 (1993).

2. M. Doyle and Y. Fuentes, J. Electrochem. Soc., 150, A706 (2003).

3. W. Fang, O. J. Kwon, and C. Y. Wang, Int. J. Energy Res., 34, 107 (2010).

4. G. Ning and B. N. Popov, J. Electrochem. Soc., 151, A1584 (2004).

5. S. Santhanagopalanl, Q. Guo, P. Ramadass, and R. E. White, J. Power Sources, 156, 620 (2006)

6. M. Guo, G. Sikha, and R. E. White, J. Electrochem. Soc., 158, A122 (2011).

7. N. A. Chaturvedi, R. Klein, J. Christensen, J. Ahmed, and A. Kojic, IEEE Control Syst. Mag., 30, 49 (2010).

8. S. K. Rahimian, S. Rayman, and R. E. White, J. Power Sources, 224, 180 (2013).

9. T. R. Tanim, C. D. Rahn, and C. Y. Wang, J. Dyn. Syst. Meas. Control, 137, 011005 (2015)

10. N. Baba, H. Yoshida, M. Nagaoka, C. Okuda, and S. Kawauchi, J. Power Sources, 252, 214 (2014)

11. A. C. Arenas, S. Onori, Y. Guezennec, and G. Rizzoni, J. Power Sources, 278, 473 (2015).

12. J. Marcicki, A. Bartlett, M. Canova, A. T. Conlisk, G. Rizzoni, Y. Guezennec, X. G. Yang, and T. Miller, ECS Trans., 50, 235 (2013).

13. Y. Shi, G. Prasad, Z. Shen, and C. D. Rahn, American Control Conference, San Francisco, CA, 356 (2011).

14. L. O. Valøen and J. N. Reimers, J. Electrochem. Soc., 152, A882 (2005).

15. C. M. Julien, A. Mauger, K. Zaghib, and H. Groult, Inorganics, 2, 132 (2014).

16. Z. Li, N. A. Chernova, M. Roppolo, S. Upreti, C. Petersburg, F. M. Alamgir, and M. S. Whittinghama, J. Electrochem. Soc., 158, A516 (2011).

17. S. Santhanagopalan, Q. Guo, and R. E. White, J. Electrochem. Soc., 154, A198 (2007).

18. P. P. Prosini, M. Lisi, S. Scaccia, M. Carewska, F. Cardellini, and M. Pasquali, J. Electrochem. Soc., 149, A297 (2002).

19. P. Arora, B. N. Popov, and R. E. White, J. Electrochem. Soc., 145, 807 (1998).

20. K. W. Nam, W. S. Yoon, H. Shin, K. Y. Chung, S. Choi, and X. Q. Yang, J. Power Sources, 192, 652 (2009)

21. P. Albertus, J. Christensen, and J. Newman, J. Electrochem. Soc., 156, A606 (2009).

22. S. Liu, Solid State Ionics, 177, 53 (2006). 